\title{
Ideais das Crianças Mineiras no Século XX: Mudanças e Continuidades ${ }^{1}$
}

\author{
Érika Lourenço ${ }^{2}$ e \\ Mônica Yumi Jinzenji \\ Universidade Federal de Minas Gerais
}

\begin{abstract}
RESUMO - Foi feita, em 1998, a réplica de uma pesquisa realizada entre 1929 e 1944 por Helena Antipoff e em 1993 por Regina Helena de Freitas Campos, com o objetivo de investigar o impacto, nos ideais das crianças de Belo Horizonte, da ênfase que a mídia vem dando ao consumismo na sociedade contemporânea. Um questionário aberto foi aplicado a 307 crianças (151 meninas e 156 meninos) da quarta série das escolas públicas e particulares de Belo Horizonte. Os dados referentes aos ideais destas crianças foram submetidos à análise de conteúdo, por gênero, e comparados com os dados das pesquisas anteriores. Foi comprovada a hipótese de que os valores transmitidos pela mídia vêm contribuindo para mudanças nos ideais infantis ao longo do século.
\end{abstract}

Palavras-chave: ideais infantis; socialização; influência da mídia televisiva; identificação.

\section{Changes and Continuities in the Ideals of Minas Gerais's Children in the XXth. Century}

\begin{abstract}
In 1998 was replicated a research conducted by Helena Antipoff between 1929 and 1944, and by Regina Helena de Freitas Campos in 1993, with the purpose of investigating the impact of consumerism conveyed by media in contemporary society into children of Belo Horizonte's ideals. 307 fourth - graders students (151 girls and 156 boys) of private and state elementary school of Belo Horizonte answered the same scheduled interview. The data concerning children's ideals were analyzed by gender and compared with data's of previous surveys. It was proved the previous hypothesis that values transmitted by media are contributing for changes in childhood ideals alongside this century.
\end{abstract}

Key words: children's ideals; socialization; influence of televised media; identification.

Considerando o século XX em retrospectiva, podemos apontá-lo como, sobretudo, um período de mudanças. $\mathrm{Na}$ sociedade ocidental, progressivamente durante este século foi surgindo uma pluralidade de alterações em diversos aspectos da vida social e material. As pessoas passaram a se deparar com situações tais como a diminuição das diferenças entre gêneros, no que diz respeito às oportunidades de trabalho e aos comportamentos sociais e familiares esperados; a crescente urbanização e industrialização; o desenvolvimento tecnológico e científico, a expansão dos meios de comunicação de massa e a informatização de diversos setores da vida cotidiana.

No Brasil este processo de transformações também se mostrou presente, embora tenha tido um início um pouco mais tardio. Conforme Mello e Novaes (1998) as mudanças sociais no contexto brasileiro começaram a se tornar

1 O presente trabalho teve origem na pesquisa "Os ideais e interesses das crianças mineiras revisitados" apresentada no XVIII Encontro Anual Helena Antipoff, no ano de 1999. As autoras agradecem a orientação da Prof. Regina Helena de Freitas Campos, que também coordenou a aplicação dos questionários pelos alunos do quarto período de Pedagogia da UFMG / 1998. A pesquisa foi realizada com o apoio do CNPq e do Prograd - UFMG.

2 Endereço: Rua Guajajaras, 712 / 502 - Centro. Belo Horizonte - MG - CEP: 30180-100. E-mail: erikalourenco@bol.com.br visíveis a partir da década de 1930, com a adoção de uma política de centralização do poder e de promoção do desenvolvimento econômico. Estas idéias, porém, teriam se acentuado e obtido novas forças a partir da década de 1950, com o crescimento da urbanização, da industrialização, da oferta de empregos no meio urbano e das rendas médias familiares. Concomitantemente, houve mudanças nos padrões de consumo da sociedade brasileira de um modo geral. $\mathrm{O}$ aumento do poder aquisitivo, aliado à disponibilidade de novos produtos e de novas tecnologias de comunicação de massa acabou por gerar modificações também no contexto social brasileiro, passou a se caracterizar por uma maior mobilidade e se abriu para novas possibilidades de relacionamentos tanto no âmbito familiar como no âmbito social mais extenso.

Esta dinâmica de transformações teve impacto nos padrões familiares e também nas concepções de infância que estiveram em vigência ao longo do século. Enquanto, segundo Berquó (1998), a família foi adotando configurações cada vez mais diversificadas em relação ao tradicional modelo nuclear, a infância e a adolescência viram-se, de acordo com Castro (1999b) cada vez mais inseridas socialmente, ganhando visibilidade, voz e um novo status neste país modernizado.

Mello e Novaes (1998) mencionam, com pertinência, o papel da mídia em todo este processo de transformações 
sociais. De acordo com estes autores, a partir da segunda metade do século, com o crescimento da concorrência entre as empresas no país, a classe média tornou-se o grande alvo das propagandas, sendo estas veiculadas principalmente pela televisão. Esta tornou-se cada vez mais acessível como meio de entretenimento, passando a fazer parte do cotidiano dos brasileiros, de modo que, na década de 1970,75\% dos lares já possuíam um aparelho de tv. A tecnologia televisiva passou, progressivamente a ter preponderância sobre outras formas de diversão e mesmo sobre os meios de educação e os momentos de diálogo familiar, tornando-se um importante veículo de divulgação de valores morais, éticos e políticos, em sua maioria, utilitários, contribuindo para a determinação das atitudes e dos comportamentos de seus espectadores. A televisão, transmitindo valores tão utilitaristas, tanto em seus comerciais como em seus programas, viria então contribuindo para a transformação da sociedade contemporânea em uma sociedade essencialmente de consumo.

Completando este quadro, Castro (1999b) argumenta que o mercado vem produzindo objetos de consumo que atendem cada vez mais às necessidades específicas não só dos adultos, como também das crianças e jovens. Com a divulgação desses produtos pela mídia televisiva, crianças e jovens estariam então recebendo o status de consumidores, o que colaboraria para sua maior visibilidade no mundo social e para o que a autora considera um adiantamento da cidadania destes sujeitos, que, de outro modo, só seriam considerados aptos para conduzir suas próprias vidas quando atingissem a maioridade.

Vemo-nos assim, conforme essas colocações, diante de um quadro um tanto curioso: o desenvolvimento tecnológico $\mathrm{e}$, mais especialmente, a sua visibilidade por meio da televisão, são acusados de transformar a sociedade brasileira em uma sociedade de consumo. Esta transformação viria se dando através da divulgação de valores utilitaristas, da apresentação de modelos hedonistas e da grande importância dada às características externas, que podem ser identificadas à primeira vista, tais como beleza, força física e posse de bens materiais, o que culminaria com a ênfase no ter (possuir tais características) como indicador principal de um status, de um lugar social. Este quadro, por sua vez, estaria gerando uma contradição, pois, ao mesmo tempo em que massifica a população com a apresentação destes modelos, o acesso à tecnologia, à própria televisão e ao mundo de consumo que ela divulga, confere à infância um lugar social diferente daquele que tradicionalmente vinha sendo atribuído a ela, de sujeito em formação, de quem tem que esperar a idade adulta para assumir sua cidadania. Este novo lugar, conforme as colocações de Castro (1999b), por um lado, está relacionado a uma inserção da criança no mundo do consumismo, por outro lado implica também em uma inserção na dinâmica do cenário social, o que, segundo a autora, tem uma dimensão que pode ser considerada positiva, já que, com isto, a criança vem ganhando espaço para se expressar e há o movimento cada vez maior no sentido de defesa dos seus direitos e necessidades.
Deparando-nos com este quadro, ficamos curiosas acerca de como estas transformações ocorridas no contexto social brasileiro ao longo do século XX vêm tendo impacto na infância. Assim, o objetivo deste trabalho foi investigar as mudanças nos ideais das crianças de Belo Horizonte, comparando dados sobre os mesmos obtidos no decorrer das décadas de 1930 e 1940 (Lustosa, Cunha \& Morais, 1951), com dados obtidos no início da década de 1990 (Campos,1996) e no seu final em 1998. Segundo Antipoff, os ideais das crianças mineiras, definidos pela identificação com modelos e pelos planos que fazem para o futuro, eram, até a primeira metade do século XX, construídos a partir da inserção na família, na escola e na igreja. Campos, no início da década de 1990, observou que estava havendo uma diminuição do lugar da família e da escola como tradicionais fontes de modelos de identificação para as crianças, lugar este que vinha sendo assumido pela mídia, num movimento que teria se iniciado com as transformações sociais e econômicas ocorridas a partir da segunda metade do século. Levantamos então a hipótese de que, no final da década de 1990, este novo perfil dos ideais das crianças mineiras identificado por Campos teria se acentuado, uma vez que, segundo Castro (1999c), as crianças, tendo reduzidas as oportunidades de brincar ao ar livre, tiveram aumentado o seu tempo de exposição aos programas de televisão. Com isto, teria aumentado também o contato das crianças com o novo ritmo das mudanças promovido pela mídia, criando e transmitindo novas necessidades de consumo e de atualização dos produtos tecnológicos.

\section{Metodologia}

Uma vez que pretendíamos comparar os resultados de nossa pesquisa com aqueles obtidos nas décadas de 1930 e 1940 e no início da década de 1990, como instrumento para obtenção de dados, utilizamos o mesmo questionário de perguntas abertas aplicado por Antipoff e seus colaboradores no período entre 1929 e 1944 (Lustosa e cols., 1951) e por Campos em 1993 (Campos, 1996) em suas pesquisas sobre os ideais e interesses das crianças mineiras.

As questões que analisamos nesta pesquisa, referentes aos ideais infantis, foram as seguintes: Com que pessoa você gostaria de parecer? Por que? Com que pessoa você não gostaria de parecer? Por que? Quando for grande, o que você quer ser? Por que?

Em 1998 responderam ao inquérito, 307 alunos - 156 meninos e 151 meninas - da quarta série primária das escolas públicas e particulares de Belo Horizonte, com idades variando entre 09 e 15 anos. O critério para escolha dos sujeitos foi o fato de estarem cursando a quarta série primária, o mesmo critério utilizado nas pesquisas anteriores.

As respostas dadas às questões que remetiam aos ideais dos estudantes foram submetidas à análise de conteúdo. Para isto, tentamos manter, sempre que possível, as mesmas categorias de análise propostas por Antipoff na década de 1930, fazendo a diferenciação das respostas por gênero. Buscando evitar a interpretação das categorias estabelecidas na 
Tabela 1. Indicação de modelos atrativos, por gênero, feita por crianças da quarta série primária, Belo Horizonte, 1929, 1944,1993 e 1998.

\begin{tabular}{|c|c|c|c|c|c|c|c|c|c|c|}
\hline \multirow{2}{*}{ Modelo Atrativo } & \multicolumn{2}{|c|}{$1929(\%)$} & \multicolumn{2}{|c|}{$1934(\%)$} & \multicolumn{2}{|c|}{$1939(\%)$} & \multicolumn{2}{|c|}{$1944(\%)$} & \multicolumn{2}{|c|}{$1998(\%)$} \\
\hline & $M$ & $\mathbf{F}$ & $M$ & $\mathbf{F}$ & $M$ & $\mathbf{F}$ & $M$ & $\mathbf{F}$ & M & $\mathbf{F}$ \\
\hline Familiares & 49,3 & 42,4 & 37,0 & 38,0 & 27,3 & 32,4 & 24,5 & 32,3 & 19,9 & 21,2 \\
\hline A rtistas ou atletas & 2,5 & 3,5 & 2,0 & 1,5 & 1,9 & 3,4 & 1,6 & 2,0 & 37,2 & 47,0 \\
\hline Ninguém, si mesmo & 7,0 & 1,8 & 21,6 & 16,2 & 7,8 & 5,0 & 9,3 & 5,4 & 32,7 & 27,2 \\
\hline Colegas, amigos & 5,3 & 13,0 & 11,9 & 10,9 & 9,1 & 10,2 & 7,0 & 13,6 & 0,6 & 2,6 \\
\hline D eus, santos & 5,3 & 5,2 & 11,9 & 9,1 & 21,7 & 22,3 & 20,3 & 22,4 & 2,6 & 0,7 \\
\hline Pessoas ilustres & 11,4 & 5,9 & 5,6 & 0,6 & 17,8 & 3,0 & 20,2 & 3,0 & 1,3 & - \\
\hline Professora & 3,3 & 21,5 & 1,5 & 11,5 & 2,5 & 13,2 & 2,1 & 9,5 & - & 0,7 \\
\hline Outros & 15,9 & 6,7 & 8,5 & 12,2 & 11,9 & 10,5 & 15,0 & 11,8 & 5,8 & 0,7 \\
\hline Total (n) & 322,0 & 438,0 & 68,0 & 721,0 & 709,0 & 911,0 & $1.216,0$ & 1482,0 & 156,0 & 151,0 \\
\hline
\end{tabular}

Fontes: Lustosa e cols., 1951; questionários aplicados pelos alunos do $4^{\circ}$ período de Pedagogia/ UFMG, 1998.

década de 1930 a partir da sua conceituação vigente na atualidade, demos especial atenção à forma pela qual Helena Antipoff e seus colaboradores definiram as categorias usadas por eles na análise. Vale ressaltar que estas, ao longo dos textos de Antipoff, aparecem acompanhadas não só de breves definições, como também de exemplos de respostas que nas categorias se enquadram, e de tabelas com as repostas mais comuns que apareciam nas categorias com maior porcentagem de respostas (Antipoff, 1930 e Lustosa e cols., 1951). Assim, para cada uma das respostas que obtivemos, buscamos verificar se apareciam entre as mencionadas por Helena Antipoff. Quando isto não acontecia, buscávamos por respostas semelhantes. Em alguns casos, julgamos necessária a criação de novas categorias, pois as respostas que analisávamos estavam relacionadas ao desenvolvimento tecnológico pelo qual a nossa sociedade passou nas últimas décadas e, definitivamente, não se enquadravam nas categorias estabelecidas por Antipoff.

Os resultados obtidos foram comparados com aqueles disponíveis nos relatórios de Antipoff (1930), Lustosa e cols. (1951) e Campos (1996).

\section{Resultados}

\section{Indicação de modelos atrativos}

Nas pesquisas realizadas por Antipoff e sua equipe no começo do século (Lustosa e cols., 1951), conforme a tabela 1, a família era apontada pelas crianças, de um modo geral, como a grande agência fornecedora de modelos, seguida da escola, na pessoa da professora e dos colegas, e da igreja, nas pessoas de Deus, Jesus e de santos, resultados em torno dos quais aparecem a maioria das respostas apresentadas pelas crianças nas décadas de 1930 e 1940.

As respostas dadas pelas crianças em 1998 apontam que tanto meninas $(47 \%)$ como meninos $(37,2 \%)$ consideram como modelos identificatórios, em primeiro lugar, artistas de televisão e cinema, cantores e atletas, pessoas com quem elas têm contato através da mídia, que vem se mostrando cada vez mais presente como agência de socialização. Embora as crianças de um modo geral indiquem todos es- tes modelos, notamos a preferência dos meninos pela escolha de atletas (jogadores de futebol e basquete) e a preferência das meninas pelas cantoras e atrizes de cinema.

Em segundo lugar, as crianças de ambos os gêneros não escolheram modelos, dizendo estar bastante "satisfeitas consigo mesmas" e "não querer parecer com ninguém". Como terceira opção, as crianças disseram querer se parecer com pessoas de sua própria família, mostrando que, embora em uma escala menor do que tradicionalmente, a família ainda atua como fonte de modelos para as crianças.

De um modo geral, as respostas dadas em 1998 revelam uma mudança nos padrões de escolha de modelos pelas crianças mineiras em relação às décadas de 1930 e 1940, seguindo uma tendência que já se mostrara presente na pesquisa realizada por Campos (1996), como nos mostra a tabela 2. A família, ainda aparecendo entre as três opções mais frequientes na década de 1990, parece estar perdendo a hegemonia que possuía na apresentação de modelos para as crianças, enquanto seu lugar vem sendo ocupado por pessoas com quem as crianças têm contato através da mídia. Ao mesmo tempo em que a família, também a escola e a igreja, tradicionais agências socializadoras, vêm perdendo consideravelmente seu papel, mostrando pouca influência sobre as escolhas infantis.

Tabela 2. Indicação de modelos atrativos, feita por crianças da quarta série primária, Belo Horizonte, 1929, 1944, 1993 e 1998.

\begin{tabular}{lrrrr}
\hline Modelo atrativo & $\begin{array}{r}\mathbf{1 9 2 9} \\
\mathbf{( \% )}\end{array}$ & $\begin{array}{r}\mathbf{1 9 4 4} \\
\mathbf{( \% )}\end{array}$ & $\begin{array}{c}\mathbf{1 9 9 3} \\
\mathbf{( \% )}\end{array}$ & $\begin{array}{c}\mathbf{1 9 9 8} \\
\mathbf{( \% )}\end{array}$ \\
\hline Familiares & 45,8 & 28,4 & 21,2 & 20,5 \\
A rtistas ou atletas & 3,0 & 1,8 & 44,1 & 42,0 \\
N inguém, si mesmo & 4,4 & 7,3 & 27,0 & 30,0 \\
Colegas, amigos & 11,6 & 10,3 & 5,9 & 1,6 \\
D eus, santos & 5,3 & 21,6 & - & 1,6 \\
Pessoas ilustres & 8,6 & 11,9 & - & 0,7 \\
Professora & 12,4 & 5,8 & - & 0,3 \\
Outros & 8,9 & 13,2 & 1,8 & 3,3 \\
\hline Total (n) & $\mathbf{7 5 5 , 0}$ & $\mathbf{2 6 9 8 , 0}$ & - & $\mathbf{3 0 7 , 0}$ \\
\hline
\end{tabular}

Fontes: Antipoff, 1930; Lustosa e cols., 1951; CAMPOS, 1996; questionários aplicados pelos alunos do 4 período de Pedagogia/ UFMG, 1998. 
Tabela 3. Motivos para escolha de modelos atrativos, por gênero, apresentados por crianças da quarta série primária, Belo Horizonte, 1929, 1934, 1939, 1944 e 1998.

\begin{tabular}{|c|c|c|c|c|c|c|c|c|c|c|}
\hline \multirow{2}{*}{ Modelo Atrativo } & \multicolumn{2}{|c|}{$1929(\%)$} & \multicolumn{2}{|c|}{$1934(\%)$} & \multicolumn{2}{|c|}{$1939(\%)$} & \multicolumn{2}{|c|}{$1944(\%)$} & \multicolumn{2}{|c|}{$1998(\%)$} \\
\hline & $M$ & $\mathbf{F}$ & $M$ & $\mathbf{F}$ & $M$ & $\mathbf{F}$ & $M$ & $\mathbf{F}$ & $M$ & $\mathbf{F}$ \\
\hline Q ualidades exteriores & 14,4 & 19,3 & 13,0 & 21,0 & 9,0 & 17,0 & 10,0 & 15,4 & 4,5 & 46,4 \\
\hline M otivos egocêntricos & 8,0 & 3,4 & 13,6 & 12,0 & 4,0 & 4,6 & 6,3 & 4,7 & 35,3 & 21,2 \\
\hline A ptidão física & - & - & - & - & - & - & - & - & 14,1 & 2,6 \\
\hline Qualidades intelectuais & 18,9 & 12,5 & 11,4 & 9,4 & 20,5 & 6,8 & 19,4 & 7,0 & 8,3 & 3,3 \\
\hline Qualidades morais & 36,5 & 58,3 & 28,1 & 31,9 & 36,1 & 38,8 & 30,0 & 42,8 & 8,3 & 9,9 \\
\hline M otivos religiosos & - & - & - & - & 9,5 & 6,2 & 10,0 & 10,3 & 3,8 & 4,0 \\
\hline Simpatia ou amizade & 18,3 & 10,0 & 7,9 & 10,3 & 8,1 & 8,6 & 4,3 & 6,1 & 10,3 & 8,6 \\
\hline Porque são felizes, acarinhados & - & - & - & - & - & - & 0,4 & - & 2,6 & 0,7 \\
\hline Porque D eus me fez assim & - & - & - & - & - & - & 4,7 & 2,6 & 2,6 & - \\
\hline O utras respostas & 3,8 & 0,2 & 25,3 & 15,0 & 12,4 & 12,7 & 14,8 & 11.3 & 10,3 & 3,3 \\
\hline Total (n) & 322,0 & 438,0 & 645,0 & 753,0 & 700,0 & 911,0 & $1.216,0$ & 1483,0 & 155,0 & 151,0 \\
\hline
\end{tabular}

Fontes: Lustosa e cols., 1951; questionários aplicados pelos alunos do $4^{\circ}$ período de Pedagogia/ UFMG, 1998.

\section{Motivos para indicação de modelos atrativos}

Na pesquisa de 1998, qualidades exteriores como a beleza, foram as mais citadas pelas meninas $(46,4 \%)$ como razão para escolha de modelos. Em segundo lugar $(21,2 \%)$ apareceram motivos egocêntricos, relacionados à própria criança, manifestando-se em expressões tais como "porque é da minha família" ou "porque me dá coisas". Para os meninos, os motivos para eleição de modelos foram, em primeiro lugar, egocêntricos $(35,3 \%)$ e, em segundo, o desejo de ter a aptidão física do modelo indicado, sobretudo aquelas concernentes às habilidades para os esportes $(14,1 \%)$.

Como indicado na tabela 3 , percebemos fortes mudanças nas justificativas apresentadas pelas crianças para escolhas de modelos, indicando variações naquilo que elas consideram valores. Na primeira metade do século, a grande maioria das crianças, meninos e meninas, identificavase com as pessoas principalmente pelos seus valores mo- rais, como bondade, honestidade e coragem. Qualidades intelectuais e qualidades exteriores também apareciam como justificativas, mas em porcentagens bastante inferiores àquelas das qualidades morais. Na década de 1990 este quadro parece haver se invertido, apresentando meninos e meninas repostas bastante diferenciadas entre si e em relação aos anos anteriores. Enquanto as meninas supervalorizaram as qualidades exteriores, estas foram bem pouco mencionadas pelos meninos (apenas 4,5\%). Estes enfatizaram mais os motivos egocêntricos, os quais foram a segunda opção das meninas, aparecendo com metade da frequiência da primeira escolha. As aptidões físicas, segunda escolha dos meninos, por outro lado, quase não foram mencionadas pelas meninas (2,6\% das respostas). Já as qualidades morais, na década de 1990, não atraíram nem aos meninos, nem às meninas. As qualidades intelectuais também foram pouco mencionadas pelas crianças e de modo especial pelas meninas, que só as mencionaram 3,3\% das vezes.

Tabela 4. Indicação de modelos repulsivos, por gênero, feita por crianças da quarta série primária, Belo Horizonte, 1934, 1939,1944 e 1998.

\begin{tabular}{|c|c|c|c|c|c|c|c|c|}
\hline \multirow{2}{*}{ Modklo Atrativo } & \multicolumn{2}{|c|}{$1934(\%)$} & \multicolumn{2}{|c|}{$1939(\%)$} & \multicolumn{2}{|c|}{$1944(\%)$} & \multicolumn{2}{|c|}{$1998(\%)$} \\
\hline & $M$ & $\mathbf{F}$ & $M$ & $\mathbf{F}$ & $M$ & $\mathbf{F}$ & $M$ & $\mathbf{F}$ \\
\hline A rtista, atleta & - & - & - & - & 0,7 & 0,6 & 34,0 & 29,8 \\
\hline N inguém & 14,6 & 12,1 & 5,5 & 2,8 & 5,1 & 3,6 & 16,0 & 12,6 \\
\hline Pessoa da família & 9,4 & 12,4 & 4,9 & 9,0 & 6,3 & 12,0 & 12,2 & 15,9 \\
\hline A migo, conhecido & 22,4 & 29,5 & 22,2 & 28,4 & 15,2 & 28,5 & 14,1 & 22,5 \\
\hline Pessoa histórica & 2,5 & 1,5 & 8,5 & 4,0 & 6,9 & 1,6 & 3,8 & 1,3 \\
\hline M al educada, ladrão & 14,1 & 9,7 & 21,1 & 16,5 & 14,4 & 15,2 & 4,5 & 8,6 \\
\hline Doentes, feios & 3,6 & 3,2 & 3,9 & 3,3 & 1,8 & 1,8 & 1,9 & 0,7 \\
\hline Desconhecidos & - & - & - & - & 0,5 & 0,7 & 1,3 & - \\
\hline A nimais & - & - & - & - & - & 0,5 & 1,3 & - \\
\hline Professora & - & - & - & - & - & - & 0,6 & 0,7 \\
\hline Pobres & - & - & - & - & 0,5 & - & 0,6 & - \\
\hline Demônio & 17,5 & 18,5 & 22,2 & 26,5 & 22,8 & 21,3 & 1,3 & 0,7 \\
\hline Outros & 15,9 & 13,1 & 11,7 & 9,5 & 25,8 & 14,2 & 8,3 & 7,3 \\
\hline Total (n) & $\mathbf{6 3 3 , 0}$ & - & 705,0 & - & $1.216,0$ & - & 156,0 & 151,0 \\
\hline
\end{tabular}

Fontes: Lustosa e cols., 1951; questionários aplicados pelos alunos do $4^{\circ}$ período de Pedagogia/ UFMG, 1998. 
Tabela 5. Motivos para a indicação de modelos repulsivos por gênero, em crianças de quarta série primária, Belo Horizonte, 1934, $1939,1944,1998$.

\begin{tabular}{|c|c|c|c|c|c|c|c|c|}
\hline \multirow{2}{*}{ Modelo Atrativo } & \multicolumn{2}{|c|}{$1934(\%)$} & \multicolumn{2}{|c|}{$1939(\%)$} & \multicolumn{2}{|c|}{$1944(\%)$} & \multicolumn{2}{|c|}{$1998(\%)$} \\
\hline & $\mathbf{M}$ & $\mathbf{F}$ & $\mathbf{M}$ & $\mathbf{F}$ & $\mathbf{M}$ & $\mathbf{F}$ & $\mathbf{M}$ & $\mathbf{F}$ \\
\hline Qualidades morais & 25,8 & 28,6 & 38,4 & 44,1 & 52,9 & 50,1 & 23,7 & 23,2 \\
\hline Q ualidades exteriores & 18,6 & 28,1 & 15,1 & 19,3 & 12,5 & 16,3 & 33,3 & 22,5 \\
\hline Preocupação religiosa & 6,0 & 5,7 & 12,0 & 6,2 & 11,4 & 11,0 & 1,3 & 2,6 \\
\hline Motivos egocêntricos & 4,6 & 5,9 & 2,4 & 1,7 & 2,7 & 3,0 & 6,4 & 5,3 \\
\hline A ntipatia & 5,7 & 5,8 & 0,85 & 6,6 & 2,2 & 2,9 & 20,5 & 32,5 \\
\hline Deus nos fez iguais & - & - & - & - & 2,0 & 0,9 & - & 0,7 \\
\hline Preocupação intelectual & 3,7 & 3,8 & 7,2 & 5,9 & 1,2 & 2,3 & 0,6 & - \\
\hline São infelizes, sofrem & - & - & - & - & 1,0 & - & 1,3 & - \\
\hline Não faz o bem & - & - & - & - & 0,5 & - & - & - \\
\hline Instinto de conservação & 2,6 & 1,0 & 2,4 & 1,2 & 0,4 & - & - & - \\
\hline A versão a crimes & 2,7 & 0,5 & 7,3 & 0,2 & - & - & - & 0,7 \\
\hline O utras respostas & 19,6 & 14,1 & 5,8 & 4,2 & 2,3 & 3,2 & 5,8 & 3,3 \\
\hline $\mathrm{N}$ ão responderam & 10,3 & 6,6 & 8,8 & 6,5 & 10,4 & 9,3 & 7,1 & 9,3 \\
\hline Total (n) & 676,0 & 806,0 & - & - & $1.194,0$ & 1476,0 & 156,0 & 151,0 \\
\hline
\end{tabular}

Fontes: Lustosa e cols., 1951; questionários aplicados pelos alunos do $4^{\circ}$ período de Pedagogia/ UFMG, 1998.

\section{Indicação de modelos repulsivos}

Sendo questionadas sobre a pessoa com quem não gostariam de se parecer, podemos notar que, em 1998, crianças de ambos os gêneros citaram em primeiro lugar artistas da TV, cinema e música $(28,2 \%$ dos meninos e $29,8 \%$ das meninas). Foi grande também o número de crianças, sobretudo meninos que, em segundo lugar (16\%) não citaram pessoa alguma. Amigos e colegas foram citados em terceiro lugar pelos meninos $(22 \%)$ e em segundo lugar pelas meninas $(22,5 \%)$; estas citaram, ainda, pessoas da família em terceiro lugar $(15,9 \%)$.

Nas pesquisas realizadas por Antipoff (Lustosa e cols., 1951), como podemos observar na tabela 4, os modelos repulsivos eram escolhidos pelas crianças, sobretudo dentre os familiares, dentre aqueles personagens indicados pela igreja como repugnantes e dentre os colegas de escola. Percebemos assim, mais uma vez, a partir das respostas obtidas em 1998, que as instâncias que definem para a criança o que ela deve ou não ter como modelo não vem mais sendo a família, a escola ou a igreja, como ocorria tradicionalmente, mas a mídia.

\section{Motivos para a indicação de modelos repulsivos}

As respostas referentes aos motivos para a indicação de modelos repulsivos mostram que, nas pesquisas realizadas entre 1934 a 1944, tanto para meninos como para meninas, as qualidades morais, como considerar o modelo uma pessoa preguiçosa, viciada, covarde ou maldosa, por exemplo, eram as justificativas citadas em primeiro lugar, seguidas, em segundo lugar, pelas qualidades exteriores, tais como achar o modelo feio ou sujo. $\mathrm{O}$ terceiro motivo mais citado estava ligado às preocupações religiosas.

Os meninos, em 1998, foram mais influenciados pelas qualidades exteriores $(33,3 \%)$. Em seguida, vieram as qualidades morais $(23 \%)$ e, em terceiro lugar $(20,5 \%)$, a anti- patia, ou seja, o fato de não gostar da pessoa ou estar brigado com ela. Já no caso das meninas, $32 \%$ justificaram sua escolha pela antipatia, $23 \%$ justificaram pelas qualidades morais e $22,5 \%$, pelas qualidades exteriores, conforme podemos ver na tabela 5 .

\section{Escolha profissional}

Em 1998, a grande maioria das meninas (74,2\%) mencionou como profissões de sua preferência aquelas relacionadas à formação superior e ao "cuidar", como medicina (de modo geral), pediatria, veterinária, dentre outras. Tais profissões, segundo as categorias definidas por Antipoff (Lustosa e cols., 1951) ${ }^{3}$, podem ser consideradas profissões liberais. Esta tendência das meninas de escolher profissões liberais, considerada de um modo geral, não sofreu alterações de acordo com as pesquisas realizadas nos anos anteriores, conforme revela a tabela 6 . Há que se mencionar, no entanto, uma diferença nas profissões citadas pelas meninas na primeira metade do século e na década de 1990: nas pesquisas realizadas por Antipoff, as meninas escolhiam em primeiro lugar a profissão de professora e pianista, e tanto na pesquisa realizada por Campos em 1993, quanto na presente pesquisa, quase não houve citações destas profissões.

Em relação aos meninos, $48 \%$ optaram por ser atletas ou artistas, profissões estas que se encaixariam na categoria de profissões intermediárias definida por Antipoff (Lustosa e cols., 1951), ficando as profissões liberais como engenheiro e advogado em segundo lugar com 39,7\% das indicações. Comparando esses dados com as pesquisas realizadas entre 1929 e 1993, percebemos a inversão nesses resultados. A maior preferência pelas profissões intermedi-

3 Segundo Lustosa e cols. (1951) são profissões liberais: engenheiro, médico advogado, padre, professor, pianista, freira, pintor, escritor, etc.; são profissões intermediárias: comerciante, bancário, jogador de bola, atleta, dançarino, artista, datilógrafo, secretária, etc. 
Tabela 6. Escolha profissional, por gênero, em crianças da quarta série primária, Belo Horizonte, 1929, 1944, 1993, 1998

\begin{tabular}{|c|c|c|c|c|c|c|c|c|}
\hline \multirow{2}{*}{ Profissão } & \multicolumn{2}{|c|}{$1929(\%)$} & \multicolumn{2}{|c|}{$1944(\%)$} & \multicolumn{2}{|c|}{$1993(\%)$} & \multicolumn{2}{|c|}{$1998(\%)$} \\
\hline & $M$ & $\mathbf{F}$ & $M$ & $\mathbf{F}$ & $M$ & $\mathbf{F}$ & $M$ & $\mathbf{F}$ \\
\hline Liberal & 51,4 & 70,2 & 47,5 & 53,0 & 54,3 & 61,3 & 39,7 & 74,2 \\
\hline Intermediária & 18,9 & 17,8 & 24,4 & 8,8 & 31,4 & 30,6 & 48,7 & 23,7 \\
\hline Técnica/manual & 22,3 & 10,0 & 23,8 & 32,9 & 8,6 & 3,6 & 5,1 & 0,7 \\
\hline Outras & 7,4 & 2,0 & 4,2 & 5,1 & 5,7 & 4,5 & 6,5 & 0,7 \\
\hline Total (n) & 332,0 & 438,0 & $1.216,0$ & $1.483,0$ & 104,0 & 113,0 & 156,0 & 151,0 \\
\hline
\end{tabular}

Fontes: Antipoff, 1930; Lustosa e cols., 1951; Campos, 1996; questionários aplicados pelos alunos do 4 º período de Pedagogia/ UFMG, 1998.

árias nos dias de hoje pode ser melhor compreendida ao verificarmos que a profissão de jogador de futebol representou $83 \%$ dessa escolha, evidenciando a importância desse esporte no universo dos meninos de hoje, reflexo do prestígio social e financeiro que marca a divulgação da profissão pela mídia atualmente.

Ao relacionarmos os dados acerca da escolha profissional com os referentes à indicação de modelos, podemos perceber que, enquanto para os meninos as duas escolhas estão fortemente relacionadas, para as meninas esta relação não se apresentou tão marcante, na medida em que elas continuam optando por profissões liberais, mantendo as tendências apresentadas nas pesquisas realizadas em 1944 e 1998.

\section{Motivo para escolha profissional}

As respostas mais freqüentes dadas tanto pelos meninos quanto pelas meninas para os motivos de suas escolhas profissionais $(62,8 \%$ e $67,45 \%$ respectivamente) se assemelham àquelas encontradas por Helena Antipoff (1930) em 1929, conforme a tabela 7, estando relacionadas ao gosto pela profissão. "Porque a profissão é boa", "porque eu gosto", foram as respostas mais freqüentes, sendo consideradas por Antipoff como demasiadamente vagas e globais, que denotariam pouco esclarecimento das crianças acerca dos motivos que as levaram às suas escolhas.

As demais respostas dadas pelas crianças em 1998 apareceram com grande diferença de freqüência em relação ao motivo mais mencionado tanto por meninas como por meninos. Entre as meninas, foi citado em segundo lugar, o interesse em lidar com crianças $(8,6 \%)$ e em terceiro lugar a preocupação em ajudar os familiares $(6,6 \%)$. Entre os meninos, percebeu-se a preocupação com questões econômicas $(9,6 \%)$ em segundo lugar, e a preocupação em ajudar a família $(4,5 \%)$ em terceiro lugar. Esses resultados se assemelham aos obtidos pelas pesquisas anteriores, havendo, no entanto, entre os meninos de 1939 e 1944 o interesse em servir à Pátria, elemento que não aparece nos anos seguintes e que pode ser associado à mobilização causada pela Segunda Guerra Mundial.

Tabela 7. Motivo para escolha profissional por gênero, em crianças da quarta série primária, Belo Horizonte, $1929,1934,1939,1944,1998$.

\begin{tabular}{|c|c|c|c|c|c|c|c|c|c|c|}
\hline \multirow{2}{*}{ Motivo } & \multicolumn{2}{|c|}{$1929(\%)$} & \multicolumn{2}{|c|}{$1934(\%)$} & \multicolumn{2}{|c|}{$1939(\%)$} & \multicolumn{2}{|c|}{$1944(\%)$} & \multicolumn{2}{|c|}{$1998(\%)$} \\
\hline & $\mathbf{M}$ & $\mathbf{F}$ & $\mathbf{M}$ & $\mathbf{F}$ & $\mathbf{M}$ & $\mathbf{F}$ & $\mathbf{M}$ & $\mathbf{F}$ & $\mathbf{M}$ & $\mathbf{F}$ \\
\hline Profissão boa, gosta & 47,9 & 69,6 & 47,0 & 59,1 & 33,3 & 48,1 & 32,6 & 45,6 & 62,8 & 67,5 \\
\hline Profissão rendosa & 10,3 & 5,8 & 11,4 & 6,0 & 10,4 & 7,4 & 11,5 & 9,0 & 9,6 & 3,6 \\
\hline Socorrer necessitados & 7,2 & 5,0 & 2,3 & 3,0 & 4,7 & 6,8 & 3,4 & 6,0 & 4,5 & 6,6 \\
\hline Para voar, viajar & - & - & - & - & - & - & 4,6 & 0,2 & 3,2 & - \\
\hline Lidar com crianças & - & - & - & - & - & - & - & 6,5 & - & 8,6 \\
\hline Trabalho leve, fácil & 4,7 & 1,4 & 2,7 & 2,1 & 4,0 & 0,9 & 3,0 & 2,9 & - & 0,7 \\
\hline Profissão útil, de futuro & - & 2,6 & 2,3 & 2,9 & 3,1 & 7,8 & 1,8 & 1,8 & 1,9 & 6 \\
\hline Defender pessoas & - & - & - & - & - & - & 0,3 & - & 1,9 & 1,9 \\
\hline Ficar famoso & - & - & - & - & - & - & 0,2 & 0,3 & 1,9 & 2,6 \\
\hline Prof. /pais, eles querem & 6,2 & 1,9 & 3,9 & 0,8 & 5 & 1,7 & 2,7 & 1,4 & 3,2 & - \\
\hline A prender, ser ilustre & 2,2 & - & 0,7 & - & 2,3 & 0,7 & 1,7 & 3,3 & - & - \\
\hline Vocação & 1,8 & 3,8 & 8,4 & 8,5 & 1,9 & 1,9 & 2,5 & 2,3 & 0,6 & - \\
\hline Servir a pátria & - & 0,9 & 2,8 & 1,0 & 12,2 & 1,5 & 20,4 & 5,6 & 0,6 & - \\
\hline Preocupação religiosa & 0,9 & 1,4 & 3,1 & 2,8 & 6,4 & 3,4 & 3,7 & 3,1 & - & - \\
\hline Trabalho honesto, sério & - & 4,1 & 0,9 & 0,2 & 1,3 & 1,4 & 0,9 & 0,2 & - & - \\
\hline P/ inventar, construir & 5,4 & - & 5,5 & 7,8 & 6,6 & 1,4 & 2,5 & - & - & - \\
\hline $\mathrm{N}$ ão sabe & - & - & - & - & - & - & - & - & 1,3 & - \\
\hline R espostas deficientes & - & - & - & 4,5 & 5,5 & 2,0 & 5,4 & 4,4 & 4,5 & 1,3 \\
\hline $\mathrm{N}$ ão respondeu & - & - & 2,7 & 1,8 & 2,7 & 2,1 & 1,7 & 4,7 & 3,8 & 1,9 \\
\hline Total (n) & 322,0 & 438,0 & $\mathbf{2 9 , 0}$ & 719,0 & 717,0 & 911,0 & $1.216,0$ & 1483,0 & 156,0 & 151,0 \\
\hline
\end{tabular}

Fontes: Antipoff, 1930; Lustosa e cols., 1951; questionários aplicados pelos alunos do 4 período de Pedagogia/ UFMG, 1998. 


\section{Discussão dos resultados}

Podemos dizer que as respostas fornecidas pelas crianças a respeito dos modelos atrativos e repulsivos e a respeito da escolha profissional, representam expressões dos ideais infantis que, de acordo com Campos (1996), estão relacionados aos padrões de socialização dos grupos nos quais as crianças estão inseridas e à ressignificação e apropriação desses valores por elas.

A indicação de modelos de identificação pelas crianças na década de 1990 foi marcada principalmente pela substituição dos familiares por personagens veiculados pela mídia, mostrando, nos ideais infantis de um modo geral e mais significativamente nas meninas, um reflexo das mudanças ocorridas na sociedade contemporânea que estabelecem novos parâmetros de relação entre as crianças e a família. Dentre estas mudanças, é possível que a participação cada vez maior das mulheres no mercado de trabalho torne cada vez mais escassa a convivência das crianças com os adultos do meio familiar, fazendo com que, de acordo com Castro (1999c), a criança passe grande parte do tempo com seus pares ou sozinha, em ambientes fechados, entretidos com a televisão ou jogos eletrônicos, aparatos estes cada vez mais presentes no seu cotidiano. Relacionado a isso, segundo Belli (1999), a grande preocupação dos pais nos dias de hoje vem sendo a impossibilidade de supervisionar ou de ensinar os filhos a assistir criticamente à televisão, e esta passa a ser, segundo a autora, a "babá eletrônica". Assim, a televisão estaria veiculando valores que contribuem maciçamente para a construção dos ideais infantis nos dias de hoje.

As mudanças na sociedade contemporânea estabelecem também novos parâmetros para a relação da criança com a escola. Segundo Castro (1999d), a experiência de ir à escola podia antes ser entendida como a apreciação e aquisição dos conhecimentos produzidos pelos mais velhos, associada à importância dada aos valores culturais, que eram considerados como bens em si mesmos. Atualmente, tais valores são questionados na medida em que a experiência escolar é avaliada, pelos alunos, principalmente segundo critérios utilitaristas, ou seja, as vantagens ou utilidades dos conhecimentos escolares e a própria escola estão sendo questionados. Como conseqüência disto, a escola estaria deixando de ser considerada, no imaginário social das crianças, como local de aprendizagem ou um meio de inserção no mundo do trabalho, passando a ser vista principalmente como o lugar de encontro com os amigos. Este novo lugar ocupado pela escola no universo da criança indica a tendência de que esta instituição, assim como vem acontecendo com a família, venha a influenciar cada vez menos a criança e os seus ideais, o que já pode ser verificado na quase ausência de indicação da profissão de professora pelas meninas da década de 1990.

Outro elemento que se apresentou na análise dos dados de 1998, refere-se ao aumento na indicação de si próprios como modelos pelas crianças de hoje. Tentamos compreender este fenômeno como um dos reflexos da colaboração da mídia na criação de um espaço social específico para a infância, distinto do espaço dos adultos e idosos (Castro, 1999d). Este novo papel atribuído à criança, de sujeito ativo, possuidor de direitos e atenção específicos, pode estar contribuindo para o aumento da satisfação delas consigo mesmas e, por conseqüência, para o abandono de modelos externos, geralmente representados por adultos, com os quais estavam relacionados seus ideais no contexto do início do século XX.

Houve, em relação aos motivos dados pelas escolhas dos modelos atrativos e repulsivos, uma diferença entre meninos e meninas. Enquanto na escolha de modelos atrativos as meninas supervalorizaram as qualidades exteriores, os meninos enfatizaram os motivos egocêntricos, seguido do desejo de ter a aptidão física do modelo, não sendo este segundo motivo tão mencionado pelas meninas. Já em relação aos motivos para a indicação dos modelos repulsivos, os meninos é que indicaram qualidades exteriores, estéticas, enquanto nas meninas predominou a antipatia. Apesar das diferenças encontradas por gênero, há indicação de que as qualidades estéticas e ligadas à aptidão física são elementos que se mostram cada vez mais presentes no universo infantil, o que vem a reforçar as observações de Lehman, Silveira, Afonso e Castro (1999). Segundo estas autoras, a sociedade atual tem dispendido grande parte de sua energia para "trabalhar o corpo", reflexo da cultura do consumo, em que é dada ênfase à estética, à aparência, o que também funciona como mecanismo de pertencimento e exclusão dos indivíduos em relação a determinados grupos. É interessante também observarmos que nos motivos para a indicação dos modelos repulsivos, as qualidades morais foram citadas em segundo lugar por ambos os gêneros, mostrando que estas, embora enfraquecido em relação ao início do século, são valores que ainda se mostram significativos nos ideais infantis de hoje.

A escolha profissional é um outro indício das influências da televisão e da tendência para o consumismo que marcam o universo infantil atualmente. Segundo Castro (1999a), atualmente, a preocupação com o futuro que as crianças apresentam, remete à posse do dinheiro para o consumo, sendo este último associado à realização pessoal e à felicidade. Tal marca, entretanto, aparece de forma diferenciada para meninos e meninas. Os meninos, na escolha profissional, tal como na escolha de modelos de identificação, são influenciados pelo prestígio social e financeiro associado ao mundo do esporte - em especial o futebol - veiculado maciçamente pela televisão. Já as meninas, apesar de indicarem também, na sua maioria, modelos de identificação da mídia, ao escolherem a profissão parecem ser mais influenciadas pelo prestígio financeiro advindo de uma formação acadêmica, já que a maior escolha é pelas profissões liberais de nível superior. Tal diferenciação entre gêneros que aparece neste caso, poderia indicar uma maior maturidade das meninas com relação aos meninos, o que as poderia estar levando a perceber as dificuldades de, na vida profissional, conseguir seguir o mesmo caminho dos modelos com quem elas gostariam de se parecer, o que não 
estaria acontecendo com os meninos. No entanto, esta é uma questão que mereceria maiores investigações no futuro, já que entre os sujeitos da pesquisa houve uma variação de idades muito grande (dos 9 aos 15 anos) e as respostas obtidas não foram analisadas por grupo etário, não há elementos que permitam afirmar ser as meninas mais maduras que os meninos de mesma faixa etária.

O predomínio dos motivos vagos e gerais, tais como "porque eu gosto" ou "porque é uma profissão boa", dados às escolhas profissionais é uma tendência que se mantém ao longo das pesquisas realizadas, podendo ser interpretada pela falta de sentido, para as crianças da faixa etária pesquisada, da escolha profissional. O aumento considerável da frequiência deste tipo de reposta no final da década de 1990 (conforme já apresentado na tabela 7), entretanto, pode estar relacionado à inserção das crianças em um mundo em que é constante a renovação de demandas de consumo, em que é divulgada a renovação pela renovação, e em que, segundo Castro (1999b), o status ocupacional passa a ser um mero indicador das possibilidades de consumo, sendo que estas últimas é que definirão "quem é quem no mundo social" (p.57).

Em síntese, podemos dizer que foi comprovada a hipótese de que estaria havendo mudanças nos ideais das crianças mineiras ao longo do século XX e de que estas mudanças estariam diretamente relacionadas tanto às mudanças sociais pelas quais o país vem passando, como à presença marcante da mídia nos lares brasileiros. Tal presença, fisicamente, vem sobrepujando a presença dos pais, da escola e da igreja, e, cognitivamente vem mostrando seus efeitos, os quais, como vimos, estão se refletindo claramente nos ideais das crianças.

Vale ainda ressaltar que, pelo tamanho da amostra analisada, os resultados aqui apresentados constituem apenas uma visão panorâmica dos ideais das crianças mineiras. Embora estes resultados apontem diversas mudanças ocorridas ao longo do século nos ideais infantis, a sua ampliação para outras faixas etárias e diferentes meios sócio-econômicos, assim como as suas consequências práticas, são aspectos que merecem investigações futuras.

\section{Referências}

Antipoff, H. (1930). Ideaes e interesses das creanças de Bello Horizonte e algumas suggestões pedagógicas. Belo Horizon- te: Secretaria de Educação e Saúde Pública de Minas Geraes. (Boletim n. 6).

Belli, A. (1999). Infância em tempo de megabytes. Em Castro, Lucia Rabello de (Org.), Infância e adolescência na cultura do consumo. Rio de Janeiro: NAU.

Berquó, E. (1998). Arranjos familiares no Brasil: uma visão demográfica. Em Schwarcz, L.M. (Org.), História da vida privada no Brasil: contrastes da intimidade contemporânea, v. 4 (pp. 411 - 438). São Paulo: Companhia das Letras.

Campos, R.H.F. (1996). Impacto de transformações socioculturais no imaginário infantil (1929-1993). Psicologia e Sociedade, 8 (2), 45-62.

Castro, L.R. (1999a). Construções identitárias e a busca da felicidade na cultura de consumo. Em Castro, L.R. (Org.), Infância e adolescência na cultura do consumo (pp.105-124). Rio de Janeiro: NAU.

Castro, L.R. de. (1999b). Consumo e a infância barbarizada: elementos da modernização brasileira?. Em Castro, L.R. (Org.), Infância e adolescência na cultura do consumo (pp. 55-74). Rio de Janeiro: NAU.

Castro, L.R. de. (1999c). Infância e adolescência hoje. Em Castro, L.R. (Org.), Infância e adolescência na cultura do consumo (pp.11-22). Rio de Janeiro: NAU.

Castro, L.R. (1999d). A infância e o consumismo: re-significando a cultura. Em Castro, L.R. (Org.), Infância e adolescência na cultura do consumo (pp.189-200). Rio de Janeiro: NAU.

Lehman, L.M.S., Silveira, A.G., Afonso, A.F.L. \& Castro, L.R. (1999). Estetização do corpo: identificação e pertencimento na contemporaneidade. Em Castro, L.R. (Org.), Infância e adolescência na cultura do consumo (pp.125-140). Rio de Janeiro: NAU.

Lustosa, I., Cunha, M.A. da, Morais, M.(1951). Os ideais e os interêsses das crianças de Belo Horizonte durante o período de 1929 a 1944. Revista do Ensino, 19(200), 149-188.

Mello, J.M.C. de, Novais, F.A.(1998). Capitalismo tardio e sociabilidade moderna. Em Schwarcz, L.M. (Org.), História da vida privada no Brasil: contrastes da intimidade contemporânea, v. 4 (pp. 559-658). São Paulo: Companhia das Letras.

Recebido em 29.05.2000

Primeira decisão editorial em 25.08.2000

Versão final em 10.10.2000

Aceito em 13.10.2000 